\title{
Managing Environmental and Operational Risks for Sustainable Cotton Production Logistics: System Dynamics Modelling for a Textile Company
}

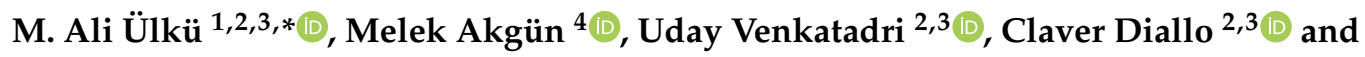 \\ Simranjeet S. Chadha 2,3 (D) \\ 1 Rowe School of Business, Dalhousie University, Halifax, NS B3H 4R2, Canada \\ 2 Centre for Research in Sustainable Supply Chain Analytics, Dalhousie University, Halifax, \\ NS B3H 4R2, Canada; uday.venkatadri@dal.ca (U.V.); claver.diallo@dal.ca (C.D.); chadha@dal.ca (S.S.C.) \\ 3 Department of Industrial Engineering, Dalhousie University, Halifax, NS B3H 4R2, Canada \\ 4 Sakarya Business School, Sakarya University, Sakarya 54050, Turkey; melekakgun@sakarya.edu.tr \\ * Correspondence: ulku@dal.ca
}

Received: 26 October 2020; Accepted: 8 December 2020; Published: 14 December 2020

\begin{abstract}
Effective management of cotton production logistics (CPL) against volatile environmental conditions while maintaining product quality and yield at acceptable costs has become challenging due to increasing global population and consumption and climate change. In CPL, the harvesting, processing, and storage of cotton are all linked, prone to various environmental risks (e.g., flooding) and operational risks (e.g., excess spraying of pesticides). Thus, it is crucial for a resilient and sustainable supply chain management to prioritize risks and chart suitable risk response strategies. For a CPL, we employ a system dynamics (SD) approach to investigate the likelihoods of environmental and operational risks and their impacts in four dimensions: variable costs, fixed costs, quality performance, and yield. Using the case of a textile company in Turkey, we demonstrate an end-to-end framework for mitigating CPL risks. SD simulation results show that increases in seed prices and machine and equipment breakdowns are the risks that most affect the unit cost, whereas pests and plant diseases most hurt cotton harvest yield. Via scenario analyses, we demonstrate that a proper risk response strategy, compared to doing nothing, may reduce variance in cotton quality by about $35 \%$ at the expense of about an $11 \%$ increase in unit cost variability.
\end{abstract}

Keywords: cost management; system dynamics; risk management; cotton production logistics; scenario analysis; supply chain

\section{Introduction}

Environmentally unsustainable production methods risk future capacities: agriculture is no exception. The most widespread non-food crop, cotton, has been a staple product instrumental for the economy, especially in developing countries. Competition in many sectors, including textiles, currently occurs between supply chains (SCs) rather than between companies. Companies cannot achieve a competitive advantage by isolating themselves from their SC partners. Pressing market and social demands and an increasing need for resiliency against supply disruptions at the global scale oblige SC partners to coordinate production, distribution, and customer service effectively.

The concept of supply chain management (SCM) has gradually gained importance since the 1980s when companies discovered the benefits of cooperation. SCM deals with the management of material, information, and financial flows in a network of suppliers, producers, distributors, and customers. Coordination and integration of these flows between and within enterprises are of critical importance for effective SCM. An SC's ability to offer end-customer goods and services of the required quality 
at a low cost depends on its success in utilizing process efficiencies and technological innovations. With price increasingly dependent on market conditions, cost management is key to efficiency and profitability. In this respect, cost management strategies have become pivotal in SCM (e.g., [1]).

Regardless of their type, size, or field of activity, all enterprises face risks. SCM deals with a complex structure exposed to various risks-from small-scale risks such as delivery delays to more significant risks such as deterioration of the entire chain [2]. In a general sense, "risk" is the probability of not achieving the desired result. Therefore, it is important to develop an effective risk management policy in SCM. Where the term "supply chain risk management" (SCRM) is relatively recent, the concept of risk management has quite a long history. While the growth of global activities may significantly reduce a SC's costs, it makes it more susceptible to risks because of increased scope and interdependencies. Companies that face increasing risks are more likely to establish partnerships and consciously participate in SC cooperation [3]. In so doing, cost-benefit trade-offs need to be carefully evaluated before adopting SCRM strategies [4].

A profitable and the most widespread non-food crop, cotton is the primary material for almost half of all textiles. More than 250 million people worldwide, mostly in developing countries, depend on cotton production for their income. The use of pesticides, high water consumption, and the conversion of natural habitat to agricultural land (deforestation) count as the most influential factors for cotton's environmental footprint. To maintain future capacity, required are more sustainable cotton production and storage methods, whereby risks are proactively managed. However, this remains an exigent and challenging task [5].

Figure 1 displays a visual of the problem we study in this paper. We segment into two main stages a textile supply chain (TSC), which uses cotton as a raw material: cotton production and textile manufacturing. Our scope is cotton production logistics (CPL) that includes seeding, growing, harvesting, and then pre-processing/storage of cotton stocks. Both the environmental risks such as drought and the operational risks such as labor shortage determine the overall quality, yield, and cost of the CPL.

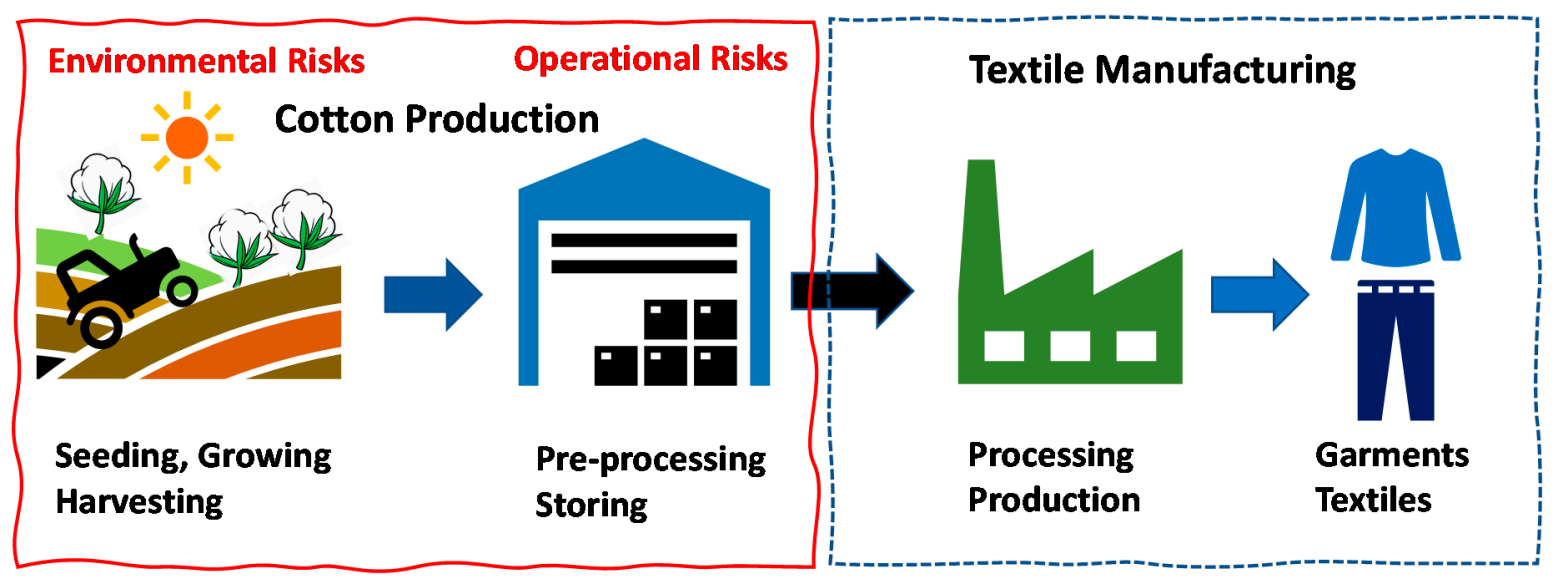

Figure 1. Visualization of the problem scope.

This paper contributes to the body of literature on supply chain risk management whereby system dynamics (SD) is employed to model complicated and confounding parameters and decision variables. To that end, as our salient contributions, (i) we analyze, via an SD modelling approach, the effects of responses to risks that may occur during CPL operations, (ii) we employ an integrated textile SC example on two essential performance criteria: cost and quality, and (iii) we provide by a case study of an end-to-end framework in developing risk response strategies.

The remainder of this paper is organized as follows: In Section 2, we provide a detailed literature review. Section 3 introduces the substructure of the study and describes building blocks of the system dynamics model (SDM) to assess and prioritize CPL risks. Drawing on Turkey as a case study, 
we discuss risk assessment and prioritization in Section 4 and then describe several risk response scenarios in Section 5. Finally, in Section 6, we summarize inferences obtained from the study and provide closing remarks.

\section{Literature Review}

The study of SCRM emerged after the 1990s and increased rapidly after 2000. SCs are largely exposed to very similar risks: according to [6], among others, 34\% of SC interruptions result from processes within the company itself, $15 \%$ from suppliers, $13 \%$ from customers, $4 \%$ from nature, $4 \%$ from governments, and $6 \%$ from the chain relationships. There are a variety of risks that may cause interruptions in SC operations. For a disaster relief SC, Peng et al. [7] use the SD model by simulating interrupted road and communication networks damaged by an earthquake. SCRs can be categorized into three types: internal, chain, and external. Internal risks result from in-house operations or from the operations themselves (c.f., [8]). These include accidents, machine and equipment (M\&E) breakdown, the failure of information technology system, human error, quality, and errors in management decisions such as the determination of the lot size, secure stock levels, financial problems, and delivery plans. Chain risks are those outside the institution but inside the SC. These result from insufficient coordination and the lack of information exchange between SC actors. Safety, the suitability of the material, time of supply, delivery problems, strike, lock-out, etc., are supplier-related risks, whereas issues related to variable demand, payments, and order processing are customer-related risks. External risks result from an interaction between the SC and the environment, such as accidents, severe weather conditions, laws and regulations, natural disasters, and wars. Bradley [9] analyzed the differences between frequent and rare risks that cause an interruption in the SC and suggested a new risk measurement and prioritization method that explains the features of rare risks.

There also exist studies on cost minimization and profit maximization in the SCRM literature. For example, to mitigate demand uncertainty in SC planning, Gupta and Maranas [10] suggested a stochastic programming-based planning model that reacts to the demand over time. Yu and Goh [11] investigated the visibility of SC and the effects of SCRs on SC performance. Wieland [12] suggested a model that ensures the selection of SC strategy based on risk probability and impact. The literature also includes studies investigating the effects of cooperation and integration, which have significant roles in the success of SCRM. Braunscheidel and Suresh [13] highlighted the impact of market tendency and learning tendency on SC agility. They also found that internal integration, external integration with the main suppliers and customers, and flexibility positively affect the SC's agility. Chen et al. [14] explored the relationship between three different types of risks-supply, demand, and process. In another study, from the perspectives of uncertainty, variability, and trust, Chen et al. [15] showed that supply risk could be mitigated by building trust in the buyer-supplier relationship in addition to information knowledge sharing. Glock and Ries [16] studied risk due to lead time variability for an SC multiple-supplier, single-buyer integrated inventory problem. Kull et al. [17] analyzed the risk of failure that results from a second-level supplier using stock and source dependence theories and reported that the supplier's excessive stock sometimes increases the risk of supply rather than decreasing it. Chen and Lee [18] suggested a multi-product, multi-stage, and multi-period model to fulfil more than one aim in multi-stage supply networks with uncertain demand and product price.

Depending on the context, SCRM is tailored according to the definition of risk used and the type of risk assessment tools available for decision-making. To that end, ample discussion of SCRs exists in the literature. For example, Kern et al. [19] developed a model for managing risks related to the supplier by attributing the risk definition, risk assessment, and risk-reducing processes to risk performance in a detailed empirical study. The effects of constantly redefining risk, its assessment, and its reduction were also modelled. Tummala and Schoenherr [20] studied SCRM processes and suggested techniques for risk assessment and management. Hallikas et al. [21] explained the risk analysis concept from both producer and supplier perspectives and investigated two approaches as computer-aided cause-effect analysis and internal audit for the risk analysis using case study and 
qualitative information. Trkman and McCormack [22] researched new techniques for estimating and defining supply risk. Their approach of assessing and classifying suppliers is based on suppliers' qualities, performance, and characteristics of the suppliers and modified according to the specific environmental conditions.

The degree of sensitivity of the SC to risks is a significant determinant for risk management strategies. Foroughi et al. [23] focused on the risks in the supplier part and investigated the reasons behind the increase in the SC sensitivity and investigated the processes of defining and evaluating threats and charting precautions to be taken in an SCRM process. Using probability theory, Grötsch et al. [24] identified conditions enabling proactive SCRM practices: The bankruptcy of past suppliers was chosen to indicate the organization's level of sensitivity. It was determined that a management control system, a logical cognitive style, and a good supplier-buyer relationship positively affect the proactive management of the bankruptcy risk of the supplier. Wagner and Neshat [25] defined SC sensitivity and comparatively measured it for companies in different categories using graph theory. In this empirical study, the authors found a negative relationship between SC sensitivity and performance but a positive relationship between SC sensitivity and risk management. After investigating the main reasons for the sensitivity and risks of SCs in the general sense, Thun and Hoenig [26] defined the possibilities and potential effects on the SC. The results were investigated separately as internal and external risks in the probability-effect matrix. Therefore, the effect of the SCRM on performance was tested. The performance difference between the companies that apply reactive and proactive risk management was shown.

SD, pioneered by Forrester [27], is a powerful modelling and simulation methodology for obtaining insights about complex systems, especially for long-term decision-making in dynamic industrial management problems. SD has been a modelling approach used to study systems' structure and behaviour with dynamic qualities that consist of interactive feedback cycles. SD modelling (SDM) aims to simulate the complex relationships within a system over a certain period and then identify possible worst-case scenarios. Furthermore, SDM helps analyze how the system reacts to external effects within a given period. The SD approach emerged from the need to understand better and analyze industrial processes and the complex structure of these processes by top decision-makers and stakeholders. With a heightened interest recently, the SD approach has been used to investigate various social, economic, and environmental systems in which the integrative idea and feedback cycles are critical to understanding the relationship between variables ([28]). The system dynamics model (SDM) can be a tool for analyzing the behaviours of complex socio-economic systems to show how organizations and politics affect actions [29] and as a powerful means for analyzing manufacturing systems [30]. Kim and Park [31], for example, successfully employed SD to investigate otherwise highly intractable inventory decisions for SC coordination. Although alternative SCRM tools exist, $\mathrm{SD}$ as an analytical method has been widely preferred by researchers for studying various operational environments (see, for example, [32-36]).

In the face of mounting challenges around sustainably matching global demand and supply, and the ever-changing landscape of the business world with environmental imperatives due to climate change, consumer pressures for sustainability, and rampant disruptions such as the COVID-19 pandemic, there is much room for research for managing risks in supply chains. To that end, this paper contributes to SCRM literature by study CPL risk mitigation via an SDM approach.

\section{Research and Case Study Background}

Cotton is the main source of natural fibre for textile supply chains (TSCs) and, as such, is a crop plant with high economic value. Moreover, cottonseed is a good source for vegetable oil for human consumption and vegetable protein in animal feed. In Turkey, cotton production is precious.

According to the Global Agricultural Information Network Report [37], “The textile industry continues to be one of the leading sectors in the Turkish economy ... Approximately 36,000 companies operate in the sector, providing about 515,000 jobs in garment production alone. Exports of 
ready-to-wear items in 2018 were [USD] 17.6 billion, and textiles were [USD] 8.4 billion, both up about four percent compared to a year before ... buyers ... prefer to work with Turkey due to geographical proximity, short response time, and good quality."

With $4.3 \%$ of the total cotton production in the world, Turkey ranks first in Europe and sixth in the world. With a total of 742,000 hectares, Turkey ranks eighth in the world in terms of planting area. Turkey also has the highest fiber yield among countries with a cotton planting area above 300,000 hectares. With cotton shares making up $62 \%$ of total fiber production in Turkey (compared to $48 \%$ globally), Turkey's textile industry generates $34 \%$ of the total export income, highlighting the value of cotton production in this developing economy [38]. Yield, quality, and cost of cotton affect the subsequent members of a TSC and its production process. Further, the risks in cotton production that affect the cost, quality, and yield also affect yarn weavers and cloth producers, distributors, and retailers. Cotton planting areas in the world are limited. Fiber production uses plant, animal, and artificial sources as alternative inputs. As cotton fibre consumption increases with the rise in population, there remains a risk of significant cotton fibre deficit worldwide.

The aim of this study, using an SD approach, is to analyze and evaluate the effects of the risks in CPL based on three primary performance criteria: yield, quality, and cost. The risk management process comprises the following steps: risk definition, measurement, assessment, evaluation, response, monitoring, and control. This process provides a successful framework in defining potential risk factors and their probability of materialization [20]. Risk management defines the risks, then measures and evaluates them; from here, it is necessary to determine the response/reaction to hedge against prioritized risks. Risk assessment is the joint function of the probability of materialization of the risk and the effect that will be created should it occur. The criteria used for the likelihood of the materialization of risks are generally digitized quantitative expressions. While the impact of the risk can be financial criteria, they can also be based on qualitative definitions such as the loss of business prestige. These criteria can be used in the conceptual modelling and evaluation of SCRs. The probability of risk materialization may be estimated using archival data, risk logs, expert opinion, or statistical data. Caution should be exercised as some of the risk management strategies may affect other risks negatively [39]. Therefore, it is also essential to understand the variability and mutual relations between the risks. Such an approach can be applied by taking threats and their sources into consideration (e.g., [2,40]), as well as their spheres of influence.

To quantify risk scores for risk prioritizations, we convert and multiply effect and probability values. Calculating risk scores in this way is beneficial in prioritizing risks and determining risk responses. However, we believe that determining which area the risk will affect, should it occur, and its level of effect (by correlating with a criterion by the field of effect in the enterprise) will yield more effective results both in risk analysis and prioritization. We note that it is a formidable task to implement a formal risk management process over the SC as a whole; various integration strategies are required for this.

\subsection{Case Study and Related Parameters}

In our case study, our focal company is 01TEX (a fictional name to preserve confidentiality), a textile enterprise established in 1989 in the Province of Adana, Turkey. 01TEX is a vertically integrated cotton production logistics: it rents cotton cropping lands on which cotton is produced and used as raw material for production in its indoor facility area of $30,000 \mathrm{~m}^{2}$. It is among the biggest textile companies in Turkey, with eight spinning factories and one denim factory with weaving, knitting, and dyeing capabilities. The company produces the raw material—its primary input—on land that it hires each year. Therefore, the transfer-selling price is dependent on the unit production cost and the quality of the cotton produced. The quality of the cotton obtained, and its price based on its cost affect the textile production stages' performance. The cotton bought is used in yarn production, and the yarn is used in fabric production. 01TEX does not sell any yarn or fabric; the fabric produced is used as an input for ready-to-wear clothing that caters to both domestic and international markets. The company management oversees a major part of the $\mathrm{SC}$, that is, from the production of cotton to delivering the 
apparels to the end consumer. Nevertheless, problems that occur during the cotton cultivation and the mobility of the cotton market prices can affect $01 \mathrm{TEX}$ 's performance. Therefore, it is necessary to estimate the management policies at the cultivation and storage stages of cotton and their results.

To preserve confidentiality, the parameter values used in this study are approximations. Cotton production costs have variable and fixed-cost (FC) components. The bulk of the costs resulting from activities related to cotton production starts in September and October with soil preparation. Then, the soil is processed once with gobble (disc harrow). The planting is performed using a sowing machine after processing the earth four times with the bed-forming machine. The planting process occurs between March and April, and thinning is performed between May and June following the planting. This process is labor-intensive. Hoeing is then carried out five times using manual labor or a hoeing machine between June and July following the thinning. Middle breaking is also performed using the bed-forming machine between June and July. With planting, the base dressing is irrigated once in June and July, twice together with the fertilization process, and four times between June and August. Labor is used in activities such as planting, thinning, hoeing, middle breaking, fertilization, disinfestation, irrigation, and harvesting in cotton production. The average use of labor is 10 hours/acre. The average machine use in cotton production is estimated as $1.5 \mathrm{~h} / \mathrm{acre}$. The seed use per acre in the enterprise is $2.60 \mathrm{~kg}$ on average, and the average kilogram cost of cotton seed is USD 9. Compound fertilizer is used as base dressing. The base dressing cost of enterprises per acre is USD 19 on average, and the top-dressing cost is USD 17, resulting in a total average cost of USD 36.

The adverse effects of diseases and pests in cotton-growing are closely related to climate conditions, such as high humidity and temperature, and loss prevention methods. Therefore, five rounds of disinfestation are required each year. The average pesticide cost is USD 58/acre, and the average irrigation costs are USD 38.40/acre. It is assumed that the enterprise plants cotton over 2500 acres per year, and it is expected to harvest $400 \mathrm{~kg} / \mathrm{acre}$. As shown in Table 1, the targeted or standard unit cost of cotton is determined to be USD 1.10/kg. According to the International Cotton Advisory Committee [41], the cost of cotton production is continuously increasing and is estimated at USD $1.5 / \mathrm{kg}$ of lint. However, the risks that occur during the planting, growing, harvesting, or cotton cause deviations from targeted levels.

Table 1. Cotton Production Costs for 01TEX Case.

\begin{tabular}{|c|c|c|c|c|}
\hline & Measure & $\begin{array}{l}\text { Quantity } \\
\text { Used }\end{array}$ & Unit Cost (USD) & $\begin{array}{c}\text { Cost } \\
\text { USD/acre }\end{array}$ \\
\hline \multicolumn{5}{|c|}{ Variable Costs } \\
\hline Seed & $\mathrm{kg} / \mathrm{acre}$ & 2.6 & 9 & 23.4 \\
\hline Fertilizer & $\mathrm{kg} / \mathrm{acre}$ & 300 & 0.12 & 36 \\
\hline Lime & ton/acre & 0.35 & 22 & 7.7 \\
\hline Labor & $\mathrm{h} /$ acre & 10 & 10 & 100 \\
\hline Electricity & kwh/acre & 1.5 & 0.42 & 0.63 \\
\hline Pesticide & times/acre & 5 & 11.6 & 58 \\
\hline Water & ton/acre & 48 & 0.8 & 38.4 \\
\hline $\begin{array}{l}\text { Transportation } \\
\text { Fuel }\end{array}$ & acre & 1 & 70 & 70 \\
\hline $\begin{array}{l}\text { Annual land } \\
\text { rent }\end{array}$ & acre & 1 & 24 & 24 \\
\hline \multicolumn{4}{|c|}{ Total Variable Cost } & USD 366.13/acre \\
\hline \multicolumn{5}{|c|}{ Fixed Costs } \\
\hline $\begin{array}{c}\text { M\&E } \\
\text { Depreciation }\end{array}$ & acre/year & 2500 & 30 & 75.000 \\
\hline Overhead & acre/year & 2500 & 44 & 110,000 \\
\hline \multicolumn{4}{|c|}{ Total Fixed Cost (for 2500 acre) } & 185,000 \\
\hline \multicolumn{4}{|c|}{ Total Cost } & USD 440.13/acre \\
\hline \multicolumn{4}{|c|}{ Unit Cost (400 kg/acre yield) } & USD 1.10/kg \\
\hline
\end{tabular}


In defining the cotton quality, six basic standard criteria are used: micronaire, fibre strength, fibre length, length uniformity, colour grade, and extraneous matter. The quality index of cotton is created based on the evaluation of these criteria as a whole. 01TEX defines its suitable quality index level for production levels as 4 (based on a quality range of 1 to 5). However, the risks incurred during cotton planting, growing, harvesting, or storage led to deviations from the targeted quality level. 01TEX management decided to implement suitable risk management strategies by determining the risk incidents that lead to deviations in targeted cost, yield, and quality metrics. A structured risk management system is developed to this end.

\subsection{Risk Identifications and Measurement}

The risk identification process is the first and most crucial stage of the risk management process. It requires preparing an extensive list of risks organized by category for business units, corporate functions, and investment projects. This stage helps form the risk profile of the company. Each risk identified requires prioritization levels to draw the attention of management. This prioritization is performed by making a risk assessment [42]. Methods used in the risk identification process vary according to the enterprise's recorded risk data, risk types, or the risk management culture in the enterprise.

Risk incidents likely to occur during CPL of O1TEX were classified as operational risks that are relatively under the control of the enterprise (the process and the chain risks, c.f., [8]), and environmental risks that may be encountered as a result of natural conditions outside the control of the enterprise. To identify those risk factors, 01TEX stroke a risk team consisting of cross-functional production managers, finance, purchasing, marketing, logistics, and cost analysis units chosen among the company management, and experts employed in professional chambers outside the enterprise. Recall Figure 1: Because 01TEX owns the farming and pre-processing/storage functions, it controls operational decisions for its CPL. Using a Delphi method (e.g., Soni et al. [43]), an interactive forecasting method that relies on a panel of experts, 01 TEX identified the risks, their likelihoods, and the ranges of impacts on the performance measures. These data directly provided to us were used as the base case for the risk simulations.

It is necessary to estimate the probability of materialization and the effects of the risks defined as critical. Risk exposure value is calculated by multiplying the likelihood of a risk with its impact. The most common way of presenting risks is the probability-effect matrix. The likelihood of occurrence may be high, intermediate, or low level. Similarly, the effects or results may be high, average or low. This process is called "risk mapping." A high, intermediate, and low $3 \times 3$ matrix is suitable for many organizations' needs, but a $5 \times 5$ matrix (or $7 \times 7$ ) may be more suitable for others. Besides, it is critical to define what is meant by "high", "intermediate" and "low" in terms of the probability and effect [44]. Additionally, the type and impact of risk over time add another layer of complexity to the analysis. For example, a risk with a negligible financial impact in the short term may have important effects on the reputation of the enterprise in the long term. Therefore, identified risks were investigated in four dimensions in terms of their effects over time. The risks that occur during cotton production have various levels of effects on fixed cost (FC), variable cost (VCs), yield, and cotton quality. See Table 2 for identified risks, likelihood of materialization, possible impact areas, and their effects.

01TEX used a 5-point Likert-type scale to measure the likelihood of the risks identified. The likelihood categories were defined as:

1 Rare, risks that are less than $0-10 \%$ likely to occur.

2 Unlikely, risks that are $10-35 \%$ likely to occur.

3 Possible, risks that are $35-60 \%$ likely to occur.

4 Likely, risks that are $60-85 \%$ likely to occur.

5 Almost sure or frequently, risks that are $85-90 \%$ likely to materialize. 
Table 2. Cotton production logistics (CPL) risks, likelihoods, and impacts for 01TEX case.

\begin{tabular}{|c|c|c|c|c|c|c|}
\hline \multirow{2}{*}{$\stackrel{2}{2}$} & \multirow[b]{2}{*}{ CPL Codes and Risks } & \multirow{2}{*}{$\begin{array}{c}\text { Risk } \\
\text { Likelihood }\end{array}$} & \multicolumn{4}{|c|}{ Risk Impact Range (min-max) } \\
\hline & & & $\begin{array}{c}\uparrow \mathrm{VC} \\
\mathrm{USD} / \mathrm{kg}\end{array}$ & $\begin{array}{c}\uparrow \text { FC } 1000 \\
\text { USD/y }\end{array}$ & $\begin{array}{c}\downarrow \text { Yield } \\
\text { (kg/acre) }\end{array}$ & $\begin{array}{l}\downarrow \text { Quality } \\
\text { (Index) }\end{array}$ \\
\hline \multirow{11}{*}{ 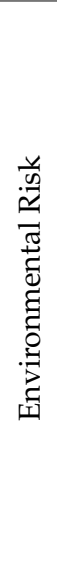 } & ER1: Flood & 4 & - & - & $10-30$ & $0.05-0.10$ \\
\hline & ER2: Pests and diseases & 4 & - & - & $6-10$ & $0.09-0.12$ \\
\hline & ER3: Drought & 3 & $2-4$ & $6-16$ & $3-6$ & $0.06-0.08$ \\
\hline & ER4: Increasing seed prices & 3 & $4-7$ & - & - & - \\
\hline & ER5: Deficient rainfall & 4 & - & - & $6-8$ & $0.10-0.14$ \\
\hline & ER6: Excess rainfall & 4 & - & - & $3-7$ & $0.05-0.08$ \\
\hline & ER7: Excess hot weather & 3 & - & - & $4-6$ & $0.07-0.10$ \\
\hline & ER8: Excess cold weather & 2 & - & - & $3-6$ & $0.05-0.08$ \\
\hline & ER9: Service interruption & 2 & - & - & $1-2$ & - \\
\hline & ER10: Seed quality problems & 2 & - & - & $4-8$ & $0.07-0.09$ \\
\hline & ER11: Deficient workforce & 5 & - & - & $3-4$ & - \\
\hline \multirow{10}{*}{ 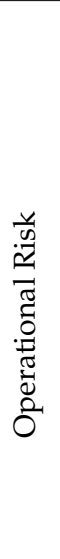 } & OR1: M\&E breakdown * & 4 & $0.2-0.5$ & $10-20$ & - & - \\
\hline & OR2: Lack of skilled workers & 3 & - & - & - & $0.02-0.03$ \\
\hline & OR3: Fire in warehouse * & 2 & - & $20-40$ & - & $0.09-0.12$ \\
\hline & OR4: Fire in field & 2 & $4-6$ & $4-5$ & $3-6$ & $0.10-0.15$ \\
\hline & OR5: Work accident & 2 & - & $40-50$ & - & - \\
\hline & OR6: Excess spraying & 3 & - & - & $6-8$ & $0.10-0.14$ \\
\hline & OR7: Deficient spraying & 4 & - & - & $3-7$ & $0.05-0.08$ \\
\hline & OR8: Pesticide residue & 3 & - & - & $4-6$ & $0.07-0.10$ \\
\hline & $\begin{array}{l}\text { OR9: Lack of humidity control } \\
\text { in warehouses * }\end{array}$ & 4 & - & - & $3-6$ & $0.05-0.08$ \\
\hline & OR10: Deficient fertilization & 4 & - & - & $5-7$ & $0.09-0.15$ \\
\hline
\end{tabular}

The Delphi panel members responded to 21 questions, one for each risk factor above in Table 2, such as "Risk factor ... (e.g., excess rainfall) is ... (e.g., possible) to occur and impact our company's performance." Then, the average of responses were taken and rounded to the nearest numerical scale. O1TEX's Delphi panel included ten members: three from top management (e.g., a board member, a unit director), two experts from outside of the company, two from middle management (e.g., a foreman), and three from the shop floor and field workers. The members responded to all of the questions, and all the members had equal weight when calculating the average response to each risk factor.

In Table 2, the likelihood of the occurrence of drought in a particular year is estimated as scale (category) 3 (i.e., 35\% at minimum, 60\% at maximum). Note that in our SD simulation, for each year, the probability of drought is randomly chosen between 0.35 and 0.60 . If this risk materializes, it leads to a decrease of a minimum of $3 \mathrm{~kg}$ and a maximum of $6 \mathrm{~kg}$ in cotton yield, a decrease of a minimum 0.09 and a maximum 0.12 points in cotton quality, an increase of a minimum of USD 2 and a maximum of USD 4/kg in VCs, and a minimum of USD 6000 and a maximum of USD 16,000 in FCs. It is necessary to create a correct risk reaction by evaluating the effects of the risks in more than one dimension and taking their interactions into account. Compared to traditional risk assessments, our process has a more complex structure in calculating risk scores; therefore, we employ an SD approach for risk assessment. 


\subsection{System Dynamics Model and Initial Conditions}

The stages of creating an SD model are as follows (c.f., [27,44]):

1. Structural analysis to understand the elements that make up the system and the relations between them. This stage benchmarks the system and finds system properties and structures at the macro scale.

2. Causal loop diagram to define the logical structure of the system. The modelling elements can be divided into level variables, rate variables, and auxiliary variables.

3. Analysis of the quantitative relations between variables by creating equations for them in mathematical form. It also reflects the curvilinear relations between variables. The creation of such relational dynamic equations facilitates computer simulation of a complex system.

4. Simulation of these flow charts and equations to adjust the control variables to investigate the effects of different factors in the system, followed by debugging.

The SD causal loop diagram consists of rate, grade or level, and auxiliary variables. Causal loop diagrams are used in the determination of feedback cycles regardless of the types of variables. Causal transformation schemes fulfil two essential functions in SD studies. First, they are used in the determination of the causal relations between the variables as the model is being developed. Second, causal loop diagrams simplify the demonstration of a model.

Figure 2 illustrates the relationships between yield, cotton quality and costs, and the negative impacts on cost and quality if those risks materialize. The logical relations of the interaction between the risks were also created. For example, for each year, the cases of excessive and deficient rainfall, drought and flood risks, or excessively hot and cold temperatures are estimated. As an example of another logical condition, we allow pesticide residue risk in our model to emerge only when disinfestation pesticides are sprayed excessively on the cotton farm.

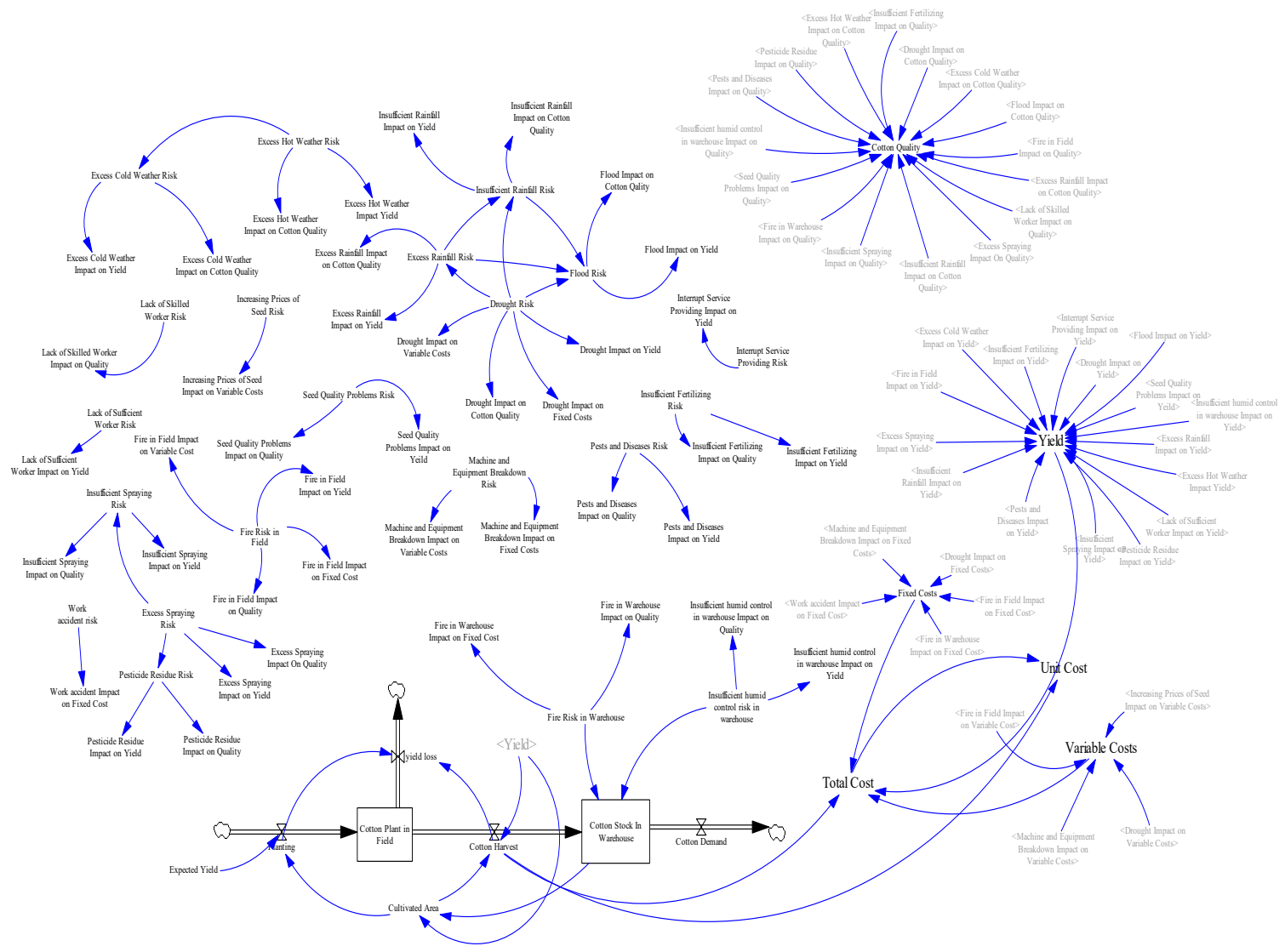

Figure 2. Causal loop diagram of CPL risks for the 01TEX case. 
Drawing on the causal loop diagrams, we develop relational equations (see Section 3.4). In this study, the total simulation horizon is 20 years. The following assumptions were employed in describing the scenarios: the planting area was 2500 acres, and the expected average cotton yield was $400 \mathrm{~kg} / \mathrm{acre}$. The VCs of cotton production expected to occur in the risk-free environment under normal conditions are USD 366.13/acre, and the annual FCs are USD 185,000/2500 acres. The expected cotton quality index is 4 . Various risk elements and the responses given to these risks affect cotton quality at multiple levels. The annual cotton planting varies between $800,000 \mathrm{~kg}$ and 900,000 $\mathrm{kg}$ according to the textile production facility's capacity. For each year, 01TEX desires to hold in its warehouse an initial stock of $50,000 \mathrm{~kg}$ of cotton.

\subsection{Model Variables and Relational Equations}

SD models contain three types of variables: flow variables which determine the change in stocks (e.g., products that enter and exit the warehouse); stock variables which represent accumulations in the system, and auxiliary variables which represent the required steps to determine the flow variables using stock variables (e.g., orders). See Table 3 for model variable notations, their definitions, and measurement units.

Table 3. Nomenclature.

\begin{tabular}{cc}
\hline Notation & Definition \\
\hline$t$ & Index for year, $t \in[0, T]$ \\
$i$ & Index for risk type, $i \in[E R 1, \ldots, E R 11] \cup[O R 1, \ldots$, OR10] \\
$A$ & The size of cotton planting area rented for the next $T$ years (in acres) \\
$A_{t}$ & The cultivated area in year $t$ (in acres) \\
$D_{t}$ & Demand for cotton in year $t$ (in kgs) \\
$F_{t}$ & Total FCs materialized during year $t$ (in dollars) \\
$H_{t}$ & Cotton harvested in year $t$ (in kgs) \\
$Q_{t}$ & Cotton quality index at year $t$ Q $Q_{t} \in\{1,2,3,4,5\}$, a scalar value \\
$V_{t}$ & Total VCs materialized during year $t$ (in USD/kg) \\
$W_{t}$ & Cotton stocked at warehouse at the start of year $t$ \\
$Y_{t}$ & Cotton yield realized during year $t$ (in kg/acre) \\
$F_{i, t}$ & Impact of risk type $i$ on FCs, during year $t$ \\
$I_{i, t}$ & Impact of risk type $i$ on initial stock, during year $t$ \\
$R_{i, t}$ & Probability of risk type $i$ materializing during year $t, 0 \leq R_{i, t} \leq 1$ \\
$Q_{i, t}$ & Impact of risk type $i$ on quality level, during year $t$ \\
$V_{i, t}$ & Impact of risk type $i$ on VC, during year $t$ \\
$Y_{i, t}$ & Impact of risk type $i$ on cotton yield, during year $t$ \\
$\bar{F}$ & Overall expected FC \\
$\bar{Q}$ & Target quality index, set at the desired level of 4 for $01 \mathrm{TEX}$ \\
$\bar{V}$ & Overall expected VC \\
$\bar{Y}$ & Target yield, set at $400 \mathrm{~kg} / \mathrm{y}$ for $01 \mathrm{TEX}$ \\
$T C_{t}$ & Total cost spent during year $t$, in dollars \\
$U C_{t}$ & Unit cost realized at year $t$, in USD/kg \\
\hline
\end{tabular}

For the next 20 years, 01TEX plans on a demand requirement of between 800,000 and 900,000 kg of cotton/year. In deciding on the size of the cotton planting area to be rented for the next year, the amount of cotton already available in the warehouse is deducted from the demand requirement of the year first. Then, the area of planting is determined with the expectation that the yield will be $400 \mathrm{kgs}$ of cotton from each acre seeded. The fixed-asset investment was made to plant approximately 2500 acres annually, and the FCs are planned accordingly.

$$
\begin{gathered}
W_{t}=W_{t-1}+H_{t}-D_{t}-\sum_{\forall i} R_{i, t} I_{i, t} \text { where } H_{t}=Y_{t} A_{t}, A_{t}=A-\left(W_{t-1} / \bar{Y}\right), \text { and } \\
Y_{t}=\bar{Y}-\sum_{\forall i} R_{i, t} Y_{i, t}
\end{gathered}
$$

with initial conditions for O1TEX taken as $W_{0}=50,000 \mathrm{kgs}, A=2500$ acres, and $\bar{Y}=400 \mathrm{kgs} /$ acre. 
Environmental and operational risks may also be effective on the yield per acre, in addition to their effects on cotton quality and costs. The expected cotton yield per acre is $400 \mathrm{~kg}$. The decrease in yield leads to the increase in unit cost in addition to the cotton cost per $\mathrm{kg}$ in the relevant planting period, in addition to reducing the amount of cotton produced. That relationship is formulated in Equation (2) above.

The amount of cotton in the warehouse is affected by specific risk incidents. The quality index, variable production costs, FCs, and the risks that may be effective on yield are presented in Table 4 with their probabilities. O1TEX set its target quality index value $(\bar{Q})$ to 4 , but the incidents that reduce that index value over time are more likely to occur if no risk-mitigation action is taken. Then, $Q_{t}$ the realized quality index at year $t$, can be calculated as in Equation (3) below.

$$
Q_{t}=\bar{Q}-\sum_{\forall i} R_{i, t} Q_{i, t}=1
$$

Table 4. Simulated total impact of the risks for 01TEX case.

\begin{tabular}{|c|c|c|c|c|c|}
\hline \multirow{2}{*}{ Risk Code } & \multirow{2}{*}{ CPS Risks } & \multicolumn{4}{|c|}{ Risk Impact } \\
\hline & & $\begin{array}{l}\text { Variable Cost } \\
\text { USD/kg/y }\end{array}$ & $\begin{array}{l}\text { Fixed Cost } \\
\text { USD/year }\end{array}$ & $\begin{array}{c}\text { Yield } \\
\text { (kg/acre) }\end{array}$ & $\begin{array}{l}\text { Cotton Quality } \\
\text { Index }\end{array}$ \\
\hline ER1 & Flood & - & - & 23.907 & 0.0739 \\
\hline ER2 & Pests and diseases & - & - & 108.176 & 1.4057 \\
\hline ER3 & Drought & 31.585 & $98,209.06$ & 51.013 & 0.6932 \\
\hline ER4 & Increasing seed prices & 35.679 & - & - & - \\
\hline ER5 & Deficient rainfall & - & - & 12.290 & 0.2168 \\
\hline ER6 & Excess rainfall & - & - & 33.079 & 0.4983 \\
\hline ER7 & Excess hot weather & - & - & 53.983 & 0.9913 \\
\hline ER8 & Excess cold weather & - & - & 8.434 & 0.1101 \\
\hline ER9 & Service interruption & - & - & 6.732 & - \\
\hline ER10 & Seed quality problems & - & - & 32.424 & 0.3875 \\
\hline ER11 & Deficient workforce & - & - & 58.985 & - \\
\hline OR1 & M\&E breakdown & 4.966 & $182,592.1$ & - & - \\
\hline OR2 & Lack of skilled workers & - & - & - & 0.1820 \\
\hline OR3 & Fire in warehouse & - & $114,754.3$ & - & 2.1347 \\
\hline OR4 & Fire in field & 5.443 & 4875.57 & 3.122 & 0.1397 \\
\hline OR5 & Work accident & - & $177,814.3$ & - & - \\
\hline OR6 & Excess spraying & - & - & 50.028 & 0.8536 \\
\hline OR7 & Deficient spraying & - & - & 29.552 & 0.4756 \\
\hline OR8 & Pesticide residue & - & - & 19.172 & 0.3399 \\
\hline OR9 & $\begin{array}{l}\text { Lack of humidity control } \\
\text { in warehouse }\end{array}$ & - & - & 56.527 & 0.8764 \\
\hline OR10 & Deficient fertilization & - & - & 76.186 & 1.6143 \\
\hline
\end{tabular}

VCs occur per acre planned. In Table 1, VCs per acre were calculated to be USD 366.13/acre. Environmental and operational risks may increase VCs over the next 20 years, as long as no risk reduction work is carried out. We calculate $V_{t}$, the realized VC in year $t$, by adding the effects of all the risks to the targeted VC $\bar{V}$. Equation (4) reflects this relationship.

$$
V_{t}=\bar{V}+\sum_{\forall i} R_{i, t} V_{i, t}
$$

FCs result from the organization structure formed to make 2500 acres of plantation per year. These consist of elements such as machine and equipment (M\&E) investment, planning, and control. The expected value of FCs is USD 185,000/year. Incidents that increase FCs may occur as long as environmental and operational risk-reducing actions are not performed in 20 years. Similar to Equation 
(4), in Equation (5), the materialized FCs accrued during the year $t$, denoted by $F_{t}$, is the sum of the targeted FCs and those additional factors due to environmental and operational risks.

$$
F_{t}=\bar{F}+\sum_{\forall i} R_{i, t} F_{i, t}
$$

Finally, in Equation (6), we express the yearly unit costs as functions of the fixed and VCs, the size of the planting area, and the harvest amount.

$$
U C_{t}=T C_{t} / H_{t} \text { where } T C_{t}=F_{t}+V_{t} A_{t}
$$

For our SD model development, we used Vensim PLE as the software for coding and analysis. Equations (1)-(6) were used to reveal the relationships between performance measures of interest. What would have happened if no risk mitigation action is taken? With the initial conditions defined above, we ran our simulation model for the planning period, 20 years. Figure 3 displays the set of those outcomes for each of the key variables: (a) cotton harvesting yield, (b) FCs, (c) VCs, (d) unit costs, and finally (e) cotton quality. Those simulated variables demonstrate the fluctuations in the ranges given in Table 2.

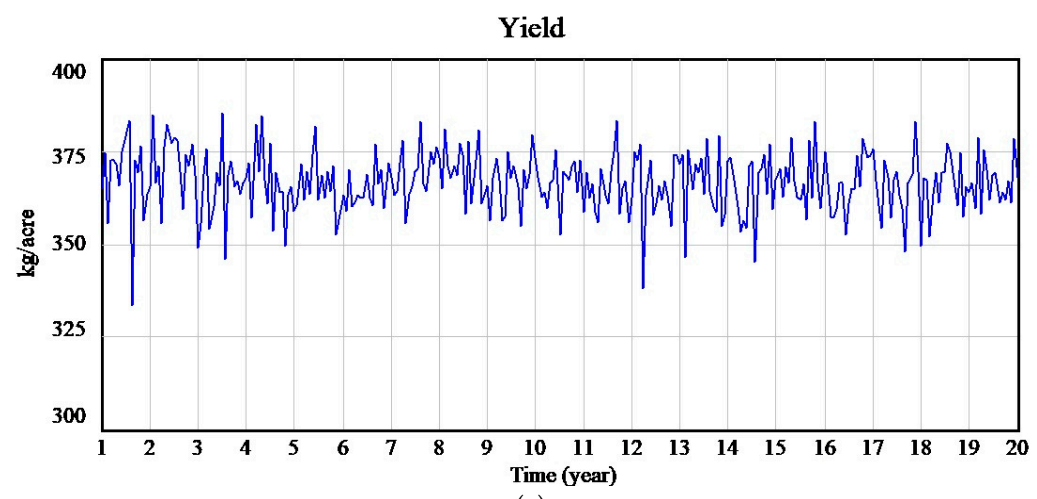

(a)

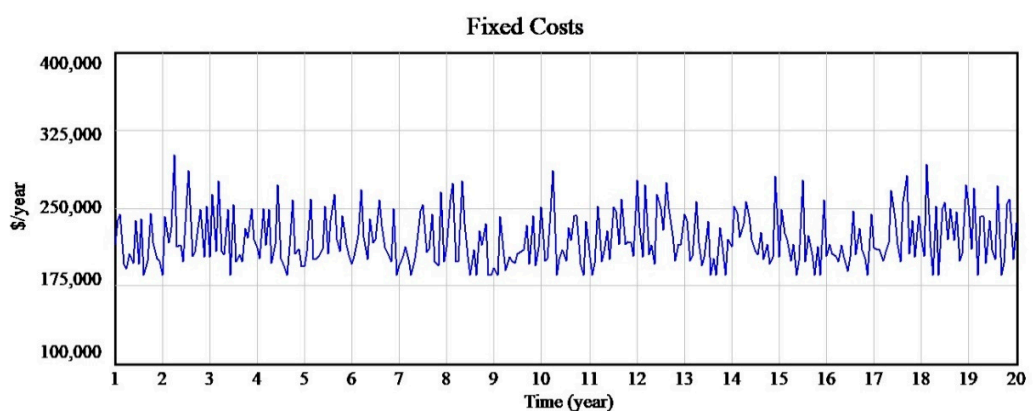

(b)

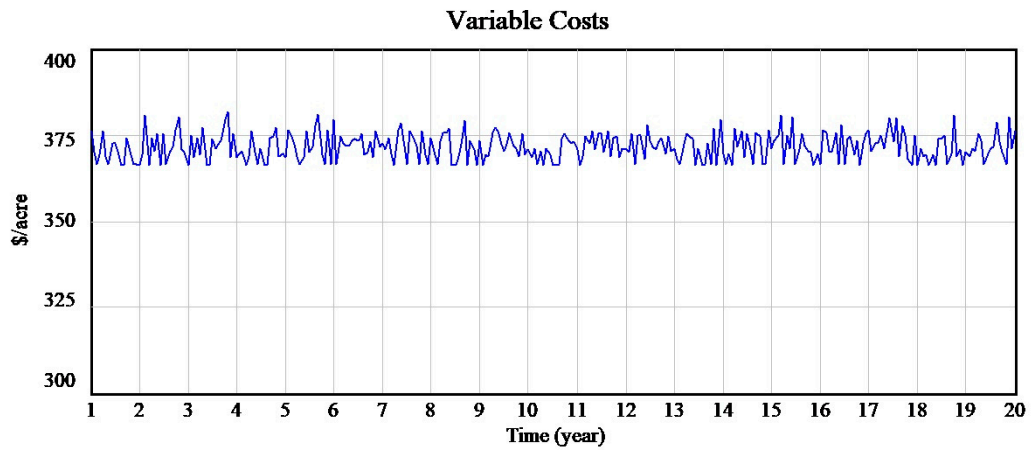

(c)

Figure 3. Cont. 


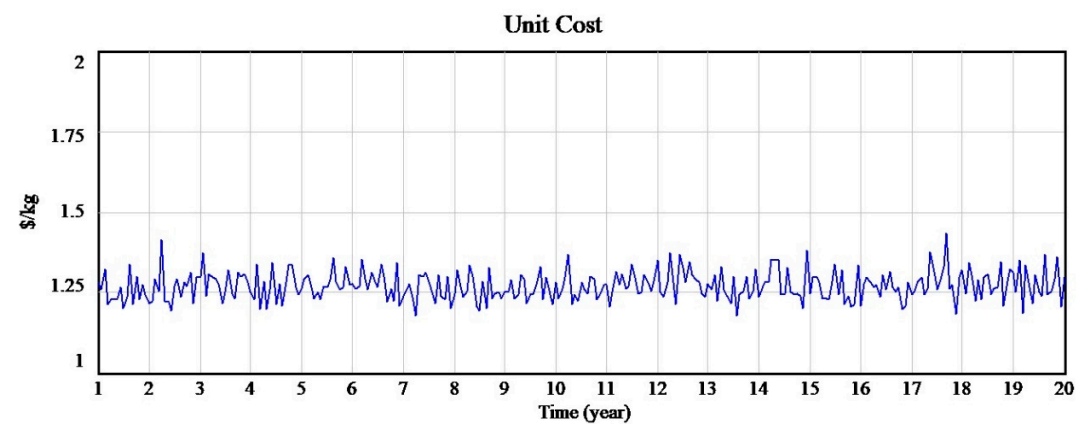

(d)

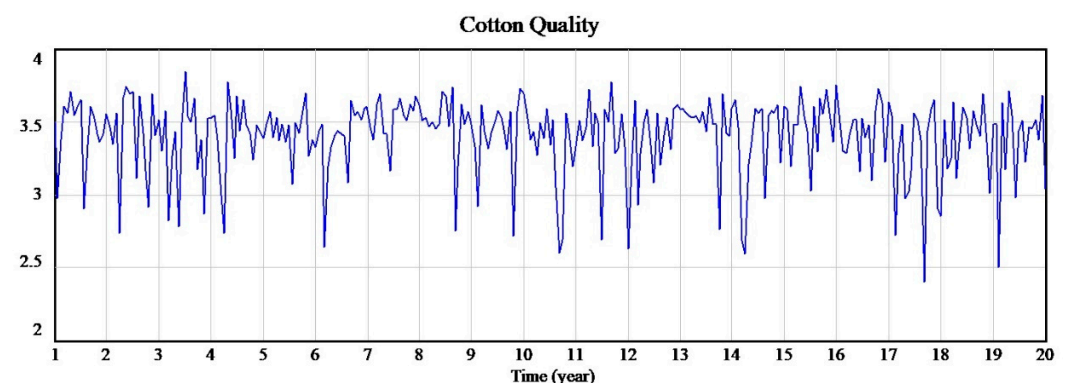

(e)

Figure 3. Simulation results for key variables when no risk mitigation action is taken.

Next, we turn our attention to identifying the most influential risk factors for 01TEX, to chart possible scenarios to be used in risk mitigation strategies.

\section{Risk Assessments and Risk Prioritization}

When the risk analysis (definition and estimation) is completed, it is necessary to compare the enterprise's risks based on its risk appetite, opportunities for recourse, and exposure level. Risk assessment is about the importance of the enterprise's risks, and whether a suitable method or alleviation option is available should a risk arise. Risk prioritization is defining risk management priorities by comparing the level of risk with previously described target risk levels and tolerance thresholds. The risk is about financial effect and probability and subjective criteria such as health and security effect, reputation effect, sensitivity, and the initial rate [42].

Table 4 presents quality, yield, FCs, VCs, and unit cost results of operational and environmental risks under initial conditions. Additionally, presented are the effects on quality, yield, FCs, and VCs with no risk-reducing action over the 20 years ahead. These results show the impact of risk types on cotton quality, costs, and total yield. The risk of an increase in seed prices (i.e., ER4) most affects the rise in VCs. Drought and fire in planting areas are the next most significant risks.

The first three risks that have a negative effect on FCs are M\&E breakdowns, work accidents, and fire that may break out in the cotton warehouses. The first three risks that may cause a negative effect on cotton yield are pests and diseases, inadequate fertilization, and deficiency in the number of workers. Lastly, the three types of risks that most negatively affect cotton quality are fires that break out in the warehouse, insufficient fertilization, and pests and diseases.

Of course, it is necessary that the risks that affect the identified performance values be investigated and evaluated by management. However, risk priorities precede planning risk responses. Determining risk responses against risk incidents, with the possibility of occurrence within the next 20 years, is among the risk management targets of 01TEX management. The cost and benefits of the risk response to $01 \mathrm{TEX}$ are now investigated under various scenarios. 


\section{Risk Response Scenarios}

Risk control may include precautions such as avoiding the risk, risk transfer, and risk financing (e.g., hedging, insurance). Risk response, also called risk treatment, includes the decision to avoid, reduce, transfer, or not accept specific risks. All information produced historically is of critical importance in defining the enterprise's tolerance towards risks and risk response. It is essential for resource efficiency to identify the limits during the initial stage of risk planning. All risks have underlying reasons. Risk teams should make an effort to determine common risk responses. First, evident risks should be defined; then, the organization should review possible responses; lastly, the organization should decide on whether other precautions should be taken [45]. Risk response strategies are generally divided into four categories:

1. Accept (A): This risk is accepted and can be tolerated without performing any other procedure. Although the risk level is high, the capability to make decisions about certain risks may be restricted, or the cost of any activation may be disproportional to the potential benefit obtained. The risk is accepted if it is not possible or practical to overcome the risk, or no response can be guaranteed as a result of the importance of the risk. We note here that Figure 3 displays the case when "Accept" is the response strategy used as a "base," the benchmark scenario for 01TEX.

2. Mitigate (M): Reduce or mitigate the effects of the risk. While the activities that cause the risk to continue within the organization, an action (check) should be performed to bring that risk to an acceptable level. Risk mitigation reduces an acceptable threshold probability and/or effect of an adverse risk incident. Taking early action to mitigate the likelihood and/or impact of a risk is generally more effective than repairing the damage after it emerges. Risk mitigation may require resources or time; thus, risk mitigation offers a trade-off between doing nothing against its cost.

3. Transfer (T): The best response to certain risks may be to transfer them. This may be performed by conventional insurance or third-party payment. This option fits well for mitigating financial risks or the risk of the assets. Risk transfer includes finding another party that wants to be responsible for the management and undertaking responsibility when the risk occurs. The goal is to make sure the risk is possessed and managed by the best party. Risk transfer generally requires the payment of a premium; this trade-off should be factored in formulating the strategy.

4. Avoid (V): Certain risks may be reduced to acceptable levels only by ending the activity. It is impossible to avoid all risks, and this approach may sometimes be cost- or time-inhibitive.

The typical performance result of the data, apart from the quality index, is unit cost because it is found by dividing the sum of fixed and VCs by the planted area times the yield in the relevant year (i.e., the amount of harvest). In this case, considering that the yield is also effective together with fixed and VCs, the quality index of unit costs was used as a secondary performance criterion. Both cotton quality and unit cotton cost are important for 01TEX.

Having identified the most influential risk types, we now develop the risk scenarios for various risk responses for each risk (see Table 5). The rationale behind these scenarios is twofold. First, O1TEX wanted to mitigate these risks; therefore, it omitted the "avoid" option as a risk response. Second, we developed these scenarios by the risk likelihood and the scope of O1TEX in mitigating them. The "base" risk response strategy accepts all the risks and therefore corresponds to a "do nothing" scenario. A pure exhaustive enumeration (combinatorial) approach would call for an additional $19,862\left(=3^{9}-1\right)$ cases. To eschew this computational burden, but more so for clarity, we adopted a sequential approach in formulating scenarios. To that end, depending on base scenario results, we assigned a risk response strategy to the most significant risk factors that hurt the criteria at hand. For Scenario 1, for example, pests and diseases, M\&E breakdown, and fire in the warehouse called for a mitigation strategy. However, a risk transfer strategy (e.g., insurance) for increases in seed prices were deemed appropriate. We similarly formulated the remaining scenarios. In the following, these scenarios, which also serve as sensitivity analyses, are described in detail. 
Table 5. Risk response strategies of the scenarios (A: Accept, T: Transfer, M: Mitigate).

\begin{tabular}{|c|c|c|c|c|c|c|c|c|c|c|c|c|c|}
\hline $\begin{array}{l}\text { Source of } \\
\text { Risk }\end{array}$ & Base & S1 & S1.1 & S1.2 & S1.3 & S1.4 & S2 & S2.1 & S2.2 & S2.3 & S3 & S3.1 & S3.2 \\
\hline $\begin{array}{c}\text { Pests and } \\
\text { diseases }\end{array}$ & A & M & $\mathrm{A}$ & M & M & M & M & M & M & M & M & M & M \\
\hline $\begin{array}{l}\text { Incr. in seed } \\
\text { prices }\end{array}$ & A & $\mathrm{T}$ & $\mathrm{T}$ & A & A & A & $\mathrm{A}$ & A & $\mathrm{A}$ & A & $\mathrm{A}$ & A & $\mathrm{A}$ \\
\hline $\begin{array}{c}\text { M\&E } \\
\text { breakdown }\end{array}$ & A & $\mathrm{M}$ & M & M & A & M & M & M & M & M & M & M & M \\
\hline $\begin{array}{c}\text { Fire in } \\
\text { warehouse }\end{array}$ & A & M & M & M & M & A & M & M & M & M & M & M & M \\
\hline Drought & $\mathrm{A}$ & $\mathrm{A}$ & $\mathrm{A}$ & $\mathrm{A}$ & A & $\mathrm{A}$ & $\mathrm{M}$ & $\mathrm{A}$ & $\mathrm{A}$ & $\mathrm{A}$ & $\mathrm{A}$ & A & $\mathrm{A}$ \\
\hline Work accident & $\mathrm{A}$ & $\mathrm{A}$ & $\mathrm{A}$ & $\mathrm{A}$ & $\mathrm{A}$ & $\mathrm{A}$ & M & $\mathrm{M}$ & $\mathrm{A}$ & $\mathrm{M}$ & $\mathrm{M}$ & $\mathrm{M}$ & $\mathrm{M}$ \\
\hline $\begin{array}{c}\text { Deficient } \\
\text { fertilization }\end{array}$ & A & $\mathrm{A}$ & $\mathrm{A}$ & A & A & M & M & M & M & A & M & M & M \\
\hline $\begin{array}{c}\text { Deficient } \\
\text { workforce }\end{array}$ & A & A & A & A & A & A & $\mathrm{A}$ & $\mathrm{A}$ & A & A & M & $\mathrm{A}$ & M \\
\hline Fire in field & $\mathrm{A}$ & $\mathrm{A}$ & $\mathrm{A}$ & $\mathrm{A}$ & $\mathrm{A}$ & $\mathrm{A}$ & $\mathrm{A}$ & $\mathrm{A}$ & A & $\mathrm{A}$ & $M$ & $\mathrm{M}$ & $\mathrm{A}$ \\
\hline
\end{tabular}

Scenario $1(\mathrm{~S} 1)$

The results of the strategies applied for reducing the highest priority risks is examined in S1. Risks of primary importance create adverse effects on the pests and diseases risk yield and quality index. This risk is at the first rank on yield and third level of importance on the quality index. Here, management plans to start a disinfestation program using a new method with an annual FC of USD 15,000 to reduce this risk. It was learnt that the effects of risk on yield and quality may be reduced by $50 \%$ when this option is applied. The risk that affects VCs most is the risk of an increase in seed prices. A response that can be developed here is risk transfer. For this, there is the possibility for long-term price lock-in with a future contract. It is estimated that this reaction will increase by USD 5000 in annual FCs; in this case, the increase in seed prices will impact. The risk of fire in the cotton warehouses has a negative effect at the first rank on cotton quality and third rank on FCs. An investment that may lead to a FC increase of USD 10,000 per year should be made to reduce this risk. In this case, the effect of a fire in a warehouse on FCs decreases to the level of USD 5000-10,000. Its impact on the quality index will decrease to the score level of $0.045-0.60$ by decreasing at a rate of $50 \%$, and its effect on the cotton stock in the warehouse to the level of $0.05-0.15 \mathrm{~kg}$.

The risks resulting from M\&E breakdowns increase FCs at the top level. An FC investment of USD 2000 should be made together with annual preventive maintenance to mitigate this risk. In this case, the increase in FCs created by M\&E breakdowns will decrease to USD 1000-2000, and the VC will decrease to USD 0.01-0.02. S1 was created by applying all of these strategies. The unit cost and quality index results were investigated should some of the risks in the sub-scenarios of S1 be accepted. The results of the failure to get no reaction against the risk of diseases and pests were investigated in sub-scenario S1.1, the acceptance of the risk of increase in seed prices in S1.2, acceptance of the risk of fire in the warehouse in S1.3, and the risk exposure results of the unit cost and quality index in case the M\&E breakdown risk is accepted were investigated in S1.4.

Scenario 2 (S2)

Among the risks of second-degree priority, the response plan against the risk of drought suggests increasing the amount of irrigation. This risk response will cause an additional VC of USD 9.60 and will reduce the effect of the risk on VCs by $50 \%$. An outsourced consulting service with an annual FC of USD 5000 will be received as a precaution of risk mitigation to reduce workplace accidents. In this case, there is a decrease of $80 \%$ in risk exposure. The need for fertilizers will be determined more accurately 
through regular soil analyses by bearing a VC of USD 4/acre against the risk of insufficient fertilization. This precaution will reduce the yield and quality risk by 1/3. S2 was created by applying all of these strategies. The results of accepting the risk of drought were investigated in S2.1, work accidents in S2.2, and deficient fertilization among the sub-scenarios of S2.

Scenario 3 (S3)

The risks with the lowest priority are the lack of sufficient workers and fire risk in the field. A wage increase may mitigate the risk of labor shortage, at the expense of a USD 5 increase in VCs. This will cause a decrease of $50 \%$ in the risk impact. There is the option to get an outsourced service to mitigate the risk of fire in the field. This option is likely to reduce risk impact at a rate of $75 \%$ while causing an increase of USD 10,000 in the annual FCs. S3 was created by applying both strategies. The results of accepting the risk of the lack of sufficient workers were investigated in S3.1, and the results of accepting the risk of fire in the cotton field were investigated in S3.2.

Table 6 displays scenario simulations over the next 20 years of planning horizon for the targeted quality index (4) and unit cost (USD 1.1/kg). Initially, all the risks negatively affect 10.99 score quality indices in 20 years. As such, the cumulative deviation from unit costs amounts to USD 3.06 per $\mathrm{kg}$. The results of the mitigation and transfer responses (S1) taken against the risks with a first-level priority reduced the deviation in the quality index to the level of 8.22. This means an improvement of $25.17 \%$ in terms of quality. However, the quality improvement at this level took the amount of deviation in unit costs to USD 3.26 by increasing at the level of $6.3 \%$. The results of accepting the pests and disease risks were investigated in S1.1 when compared to S1. An improvement occurred in the quality index deviation in this scenario compared to the initial state, but this improvement remained below the results of S1. The increase in unit costs was higher when compared to S1. According to this result, it is not advisable to accept the risk of pests and diseases. The results when the risk of an increase in seed prices is accepted are investigated in S1.2. No change occurred in S1.2 compared to S1, since the risk of an increase in seed prices does not affect the quality index. The deviation in unit costs increased at a rate of $6.0 \%$, according to the initial scenario. Accordingly, it is not recommended to apply the transfer strategy against the risk of an increase in seed prices. This risk should be accepted. There is no precaution against this risk in subsequent scenarios, and this risk remains as it is in the initial scenario.

Table 6. Total risk variances (over 20 years) of risk response scenarios.

\begin{tabular}{cccccccccccccc}
\hline $\begin{array}{c}\text { Variance } \\
\text { Type }\end{array}$ & Base & S1 & S1.1 & S1.2 & S1.3 & S1.4 & S2 & S2.1 & S2.2 & S2.3 & S3 & S3.1 & S3.2 \\
\hline Quality & 10.99 & 8.22 & 9.06 & 8.22 & 10.15 & 8.22 & 6.80 & 7.15 & 7.15 & 8.00 & 7.04 & 7.04 & 7.15 \\
\hline Unit Cost & 3.06 & 3.25 & 3.31 & 3.25 & 3.12 & 3.43 & 3.75 & 3.39 & 3.45 & 3.30 & 3.78 & 3.60 & 3.57 \\
\hline
\end{tabular}

The results of accepting the risk of fire in the warehouse were investigated in S1.3. While the quality index deviation increases at a rate of $7.6 \%$ in the simulation results of this scenario, unit cost deviation increased at a rate of $1.9 \%$. While the increase in the deviation of costs is quite low in this option, the improvement in the level of quality occurred was quite low when compared to S1.2. At this point, a choice should be made between quality improvement and unit costs. The application of the risk mitigation strategy against the risk of fire in the warehouse was applied. The results of accepting the M\&E breakdown risk are investigated in S1.4. This scenario includes the simulation results of the pests and diseases and risk of fire in the warehouse mitigation strategies. Accordingly, the same degree of deviation occurred in S1.4 with the quality index level in S1 and S1.2. However, the rate of increase in the variation in unit costs was $11.9 \%$. Therefore, the mitigation strategy should be applied and the risk should not be accepted against the risk of M\&E breakdown. In S1, the risks with the highest priority were examined. Amongst S1 and its sub-scenarios, the most suitable risk mitigation suite is S1.2. S1.2 includes mitigation strategies against pests and diseases, fire in the warehouse, and M\&E 
breakdowns. The risk of an increase in seed prices is accepted, with no risk response. S1.2 data were primarily regarded as the starting point in the design of S2.

Mitigation strategies were applied against drought, work accidents, and insufficient fertilizing risks in S2. Here, the deviation in the quality index decreased to the lowest level. According to the base scenario, the quality index deviation decreased at a rate of $38.1 \%$. However, the deviation in unit costs increased $22.3 \%$. If company management is satisfied with the increase in the level of quality achieved in return for the costs borne, the mitigation strategies in this scenario can be applied. The results of the option of accepting the drought risk were investigated in S2.1. According to the simulation results, the quality index here occurred with a lower deviation at the rate of $34.9 \%$ when compared to the base scenario. The deviation in unit costs increased by $10.5 \%$ when compared to the base scenario. This option was found suitable by the management in that it ensures a balance between cost and quality level, and it was decided to accept the risk of drought. The acceptance of the risk of work accidents in S2.2 did not create a difference on the quality index when compared to S2.1, but it led to a deviation of $12.7 \%$ more in costs when compared to the main scenario. This means that a mitigation strategy should be applied against work accidents, and the risk should not be accepted. A reduction of $27.2 \%$ occurred in the quality index when compared to the initial conditions as a result of accepting the insufficient fertilizing risk in S2.3, and the deviation increase in unit costs occurred at a rate of $7.7 \%$. While the rise in deviation in unit costs is low compared to other options, the decrease in the quality index deviation is relatively low, especially compared to S2.1. Therefore, S2.1 was taken as the basis for subsequent scenarios.

In Scenario 3, quality index variance decreased 35.91\% compared to the base scenario due to the precautions taken against the shortage of workers and fire risks in the cotton field. While it is a good result in terms of the level of quality, an increase of $23.4 \%$ in the deviation in unit costs is not regarded to be very suitable in terms of the balance between quality and costs. If the risk is accepted against the lack of sufficient workers among these risks, the quality level does not change compared to S3. Still, the increase in the deviation in costs occurs at a $17.4 \%$ rate compared to the base scenario. Finally, the quality index deviation decreased $34.9 \%$, and the deviation increase in unit costs became $16.5 \%$ when the risk of fire in the field was accepted.

Based on how much deviation from the level of quality and unit costs over the planning horizon is regarded as tolerable by management, 01TEX can decide its risk response, as shown in Table 6. The scenario that ensures the most appropriate balance between quality and unit cost is S2.1. The increase in seed prices, drought, lack of sufficient workers, and fire risks in the field are among the first four risks in the risk prioritization that should be accepted, and mitigation strategies should be activated accordingly.

\section{Concluding Remarks}

This study suggests a framework to identify, assess, and prioritize risks that occur during cotton production and proposes risk responses that affect the whole textile SC. The framework uses a simulation approach with the SDM to effectively assess cotton production risks. The model was primarily simulated to define the effects of identified risks on four performance criteria. The results show that it is not possible to mitigate all risks with high priority in terms of their impact on yield, quality, and variable and fixed costs and that a risk response that enhances quality levels and cotton yield, need also increase the costs. Therefore, assessing a single-dimension risk effect and risk response planning may not prove useful. To proactively manage and prevent this disadvantage, the effects of risks as well as their probability of realization and the business performance they affect should be well-identified, and risk response strategies should be planned accordingly.

Managing risks in supply chains fosters resilience and robustness in SC planning and execution (e.g., El Baz and Ruel [46]). Especially in the face of massive disruptions such as COVID-19, SC managers have once more realized the vital role of SCRM. Exacerbated with climate change, uncertainties mounting in SCs both from supply and demand sides call for more holistic and integrated approaches to SCRM. In this paper, we demonstrated the impact of some uncertainties in CPL of a textile SC via a case study from Turkey. However, this is all but one application using SDM, wherein the 
data are based on approximations and the experts' input. Naturally, various other approaches can be integrated into forecasting models for SCs. Depending on the type of the product, industry, market conditions, the length of the SC, and its vulnerability to environmental conditions, one model may fit better than others. For example, structural equation modelling could be another alternative to the Delphi method if the company has resources to invest in improving its forecasting process. With the advent of enhanced technology and pressing environmental and social pressures for sustainability, there is much room for research in developing analytical models that aid in the design and operation of sustainable and resilient SCs (e.g., Araz et al. [47], Ülkü and Engau [48]).

Although the operational and social risks were the focus in this paper, the issues around social risks in SCs are rampantly emerging. Especially for those industries such as agriculture and textiles that are still heavily labor-intensive in some countries, the inclusion of social risks for a holistic SCRM is required. We considered the lack of skilled labor as a parameter in this study; ultimately, this relates to the quality of the working conditions and fair wages, among others (c.f., Bhavsar et al. [49]). The COVID-19 pandemic has exacerbated the lack of skilled labor because of heightened restrictions on international workers' visas and health conditions. This again nuances the need to incorporate into SCRM some metrics related to social sustainability.

Naturally, the numerical findings and insights in this study are confined to the parameters for and the context of the 01TEX case. Nevertheless, it provides an end-to-end framework in assessing risks and formulating risk response strategies and highlights trade-offs in management objectives. An approach focusing solely on cost minimization may differ from one that places the highest cotton quality first. To that end, one limitation, and thereby future research, is to develop a more sophisticated decision method that simultaneously factors in weights or preferences over multiple decision criteria and risk response strategies. Another limitation is the accuracy of the input data. Although the Delphi method in assessing various uncertainties has its merits from practical perspectives, combining expert judgements with quantitative data, such as in structural equation modelling, may improve the consistency and accuracy of forecasts.

This study has focused on the supply side whereby the quality, yield, and cost of cotton were decision criteria in formulating the risk response strategies. Amalgamating CPL with the downstream textile manufacturing (recall Figure 1) and retailing would enlarge the SC's scope by including the demand side, enabling price, rather than cost, as a decision criterion. Such a multi-stage problem setting within which multiple SC partners act with conflicting interests would be worthy of future research. Because most SCs are currently globalized, including those in the textile industry, it would be interesting to study via SDM the management of and mitigation strategies for globally sustainable cotton production, especially in the context of social sustainability. There is an emerging concern around modern slavery in cotton production and historical child labor use in the cotton fields (e.g., Stevenson and Cole [50]). Finally, developing a robust optimization model to trade-off risks with risk mitigation costs warrants a new research extension.

Author Contributions: Conceptualization, M.A.Ü. and M.A.; methodology, M.A.; software, M.A.; validation, U.V., C.D., and S.S.C.; formal analysis, M.A.; resources, M.A.Ü.; data curation, M.A. and S.S.C.; writing-original draft preparation, M.A., M.A.Ü., and U.V.; writing-review and editing, U.V, C.D., and M.A.Ü.; visualization, M.A.; supervision, M.A.Ü.; project administration, M.A.Ü. All authors have read and agreed to the published version of the manuscript.

Funding: This research received no external funding.

Conflicts of Interest: The authors declare no conflict of interest.

\section{References}

1. Hofmann, E.; Bosshard, J. Supply chain management and activity-based costing. Int. J. Phys. Distrib. Logist. Manag. 2017, 47, 712-735. [CrossRef]

2. Waters, D. Supply Chain Risk Management, Vulnerability, and Resilience in Logistics; Replica Press: New Delhi, India, 2011. 
3. Zeng, B.; Yen, B.P.-C. Rethinking the role of partnerships in global supply chains: A risk-based perspective. Int. J. Prod. Econ. 2017, 185, 52-62. [CrossRef]

4. Wang, X.; Tiwari, P.; Chen, X. Communicating supply chain risks and mitigation strategies: A comprehensive framework. Prod. Plan. Control 2017, 28, 1023-1036. [CrossRef]

5. World Wide Fund for Nature. 2020. Available online: https://www.worldwildlife.org/industries/cotton (accessed on 20 July 2020).

6. Hendricks, K.B.; Singhal, V.R. An Empirical Analysis of the Effect of Supply Chain Disruptions on Long-Run Stock Price Performance and Equity Risk of the Firm. Prod. Oper. Manag. 2005, 14, 35-52. [CrossRef]

7. Peng, M.; Peng, Y.; Chen, H. Post-seismic supply chain risk management: A system dynamics disruption analysis approach for inventory and logistics planning. Comput. Oper. Res. 2014, 42, 14-24. [CrossRef]

8. Fan, Y.; Stevenson, M. A review of supply chain risk management: Definition, theory, and research agenda. Int. J. Phys. Distrib. Logist. Manag. 2018, 48, 205-230. [CrossRef]

9. Bradley, J.R. An improved method for managing catastrophic supply chain disruptions. Bus. Horiz. 2014, 57, 483-495. [CrossRef]

10. Gupta, A.; Maranas, C.D. Managing demand uncertainty in supply chain planning. Comput. Chem. Eng. 2003, 27, 1219-1227. [CrossRef]

11. Yu, M.; Goh, M. A multi-objective approach to supply chain visibility and risk. Eur. J. Oper. Res. 2014, 233, 125-130. [CrossRef]

12. Wieland, A. Selecting the right supply chain based on risks. J. Manuf. Technol. Manag. 2013, 24, 652-668. [CrossRef]

13. Braunscheidel, M.J.; Suresh, N.C. The organizational antecedents of a firm's supply chain agility for risk mitigation and response. J. Oper. Manag. 2009, 27, 119-140. [CrossRef]

14. Chen, J.; Sohal, A.S.; Prajogo, D.I. Supply chain operational risk mitigation: A collaborative approach. Int. J. Prod. Res. 2013, 51, 2186-2199. [CrossRef]

15. Chen, J.; Sohal, A.S.; Prajogo, D.I. Supply risk mitigation: A multi-theoretical perspective. Prod. Plan. Control 2016, 27, 853-863. [CrossRef]

16. Glock, C.H.; Ries, J.M. Reducing lead time risk through multiple sourcing: The case of stochastic demand and variable lead time. Int. J. Prod. Res. 2013, 51, 43-56. [CrossRef]

17. Kull, T.; Closs, D.J.; Kull, T.; Closs, D.J. The risk of second-tier supplier failures in serial supply chains: Implications for order policies and distributor autonomy. Eur. J. Oper. Res. 2008, 186, 1158-1174. [CrossRef]

18. Chen, C.; Lee, W. Multi-objective optimization of multi-echelon supply chain networks with uncertain product demands and prices. Comput. Chem. Eng. 2004, 28, 1131-1144. [CrossRef]

19. Kern, D.; Moser, R.; Hartmann, E.; Moder, M. Supply risk management: Model development and empirical analysis. Int. J. Phys. Distrib. Logist. Manag. 2012, 42, 60-82. [CrossRef]

20. Tummala, R.; Schoenherr, T. Assessing and managing risks using the Supply Chain Risk Management Process (SCRMP). Supply Chain Manag. Int. J. 2011, 16, 474-483. [CrossRef]

21. Hallikas, J.; Virolainen, V.; Tuominen, M. Risk analysis and assessment in network environments: A dyadic case study. Int. J. Prod. Econ. 2002, 78, 45-55. [CrossRef]

22. Trkman, P.; McCormack, K. Supply chain risk in turbulent environments-A conceptual model for managing supply chain network risk. Int. J. Prod. Econ. 2009, 119, 247-258. [CrossRef]

23. Foroughi, A.; Albin, M.; Kocakulah, M. Perspectives on global supply chain supply-side risk management. In Proceedings of the 2006 Technology Management for the Global Future-PICMET IEEE Conference, Istanbul, Turkey, 8-13 July 2006; Volume 6, pp. 2732-2740.

24. Grötsch, V.; Blome, C.; Schleper, M.C. Antecedents of proactive supply chain risk management: A contingency theory perspective. Int. J. Prod. Res. 2013, 51, 2842-2867. [CrossRef]

25. Wagner, S.M.; Neshat, N. A comparison of supply chain vulnerability indices for different categories of firms. Int. J. Prod. Res. 2012, 50, 2877-2891. [CrossRef]

26. Thun, J.H.; Hoenig, D. An empirical analysis of supply chain risk management in the German automotive industry. Int. J. Prod. Econ. 2011, 131, 242-249. [CrossRef]

27. Forrester, J.W. Industrial Dynamics; MIT Press: Cambridge, MA, USA, 1961.

28. Fagundes, M.V.C.; Teles, E.O.; De Melo, S.A.V.; Freires, F.G.M. Decision-making models and support systems for supply chain risk: Literature mapping and future research agenda. Eur. Res. Manag. Bus. Econ. 2020, 26, 63-70. [CrossRef] 
29. Sterman, J.D. Business Dynamics: Systems Thinking and Modeling for a Complex World; McGraw-Hill: New York, NY, USA, 2000.

30. Adane, T.F.; Bianchi, M.F.; Archenti, A.; Nicolescu, M. Application of system dynamics for analysis of performance of manufacturing systems. J. Manuf. Syst. 2019, 53, 212-233. [CrossRef]

31. Kim, B.; Park, C. Coordinating decisions by supply chain partners in a vendor-managed inventory relationship. J. Manuf. Syst. 2010, 29, 71-80. [CrossRef]

32. Baines, T.S.; Harrison, D.K. An opportunity for system dynamics in manufacturing system modelling. Prod. Plan. Control 1999, 10, 542-552. [CrossRef]

33. Tako, A.A.; Robinson, S. The application of discrete event simulation and system dynamics in the logistics and supply chain context. Decis. Support Syst. 2012, 52, 802-815. [CrossRef]

34. Ghadge, A.; Dani, S.; Chester, M.; Kalawsky, R. A systems approach for modelling supply chain risks. Supply Chain Manag. Int. J. 2013, 18, 523-538. [CrossRef]

35. Li, C.; Ren, J.; Wang, H. A system dynamics simulation model of chemical supply chain transportation risk management systems. Comput. Chem. Eng. 2016, 89, 71-83. [CrossRef]

36. Mehrjoo, M.; Pasek, Z.J. Risk assessment for the supply chain of fast fashion apparel industry: A system dynamics framework. Int. J. Prod. Res. 2015, 54, 28-48. [CrossRef]

37. Global Agricultural Information Network, USDA. Turkey, Cotton and Product Annual, GAIN Report\# TR9007. 2019. Available online: https://www.fas.usda.gov/data (accessed on 3 May 2020).

38. Basal, H.; Karademir, E.; Goren, H.K.; Sezener, V.; Dogan, M.N.; Gencsoylu, I.; Erdogan, O. Cotton production in Turkey and Europe. In Cotton Production; Jabran, K., Chauhan, B.S., Eds.; John Wiley \& Sons Ltd.: Hoboken, NJ, USA, 2019; pp. 297-321.

39. Chopra, S.; Sodhi, M.S. Managing risk to avoid supply-chain breakdown. Sloan Manag. Rev. 2004, 46, 53-61.

40. DuHadway, S.; Carnovale, S.; Hazen, B. Understanding risk management for intentional supply chain disruptions: Risk detection, risk mitigation, and risk recovery. Ann. Oper. Res. 2019, 283, 179-198. [CrossRef]

41. International Cotton Advisory Committee. Did You Know? 2019. Available online: https://www.icac.org/ LearningCorner/LearningCorner?CategoryId=1\&MenuId=14 (accessed on 20 May 2020).

42. Akgün, M. The Operational Risk Assessments in Manufacturing Industry. In Global Business Expansion: Concepts, Methodologies, Tools, and Applications; IGI Global: Hershey, PA, USA, 2018; pp. 653-675.

43. Soni, U.; Jain, V.; Kumar, S. Measuring supply chain resilience using a deterministic modeling approach. Comput. Ind. Eng. 2014, 74, 11-25. [CrossRef]

44. Forrester, J.W. System dynamics, systems thinking, and soft OR. Syst. Dyn. Rev. 1994, 10, 245-256. [CrossRef]

45. Hopkin, P. Fundamentals of Risk Management: Understanding, Evaluating, and Implementing Effective Risk Management; IRM Kogan Page: London, UK, 2012.

46. El Baz, J.; Ruel, S. Can supply chain risk management practices mitigate the disruption impacts on supply chains' resilience and robustness? Evidence from an empirical survey in a COVID-19 outbreak era. Int. J. Prod. Econ. 2020, 107972. [CrossRef]

47. Araz, O.M.; Choi, T.-M.; Olson, D.L.; Salman, F.S. Role of Analytics for Operational Risk Management in the Era of Big Data. Decis. Sci. 2020. [CrossRef]

48. Ülkü, M.A.; Engau, A. Sustainable supply chain analytics. In Industry, Innovation and Infrastructure. Encyclopedia of the UN Sustainable Development Goals; Leal Filho, W., Azul, A.M., Brandli, L., Lange Salvia, A., Wall, T., Eds.; Springer: Berlin, Germany, 2021. [CrossRef]

49. Bhavsar, A.; Diallo, C.; Ülkü, M.A. Towards sustainable development: Optimal pricing and sales strategies for retailing fair trade products. J. Clean. Prod. 2020, 124990. [CrossRef]

50. Stevenson, M.; Cole, R. Modern slavery in supply chains: A secondary data analysis of detection, remediation and disclosure. Supply Chain Manag. Int. J. 2018, 12, 81-99. [CrossRef]

Publisher's Note: MDPI stays neutral with regard to jurisdictional claims in published maps and institutional affiliations. 